\title{
El individuo irreductible. Extravíos del liberalismo y el socialismo modernos ${ }^{*}$
}

\author{
María Cristina López Bolivar ${ }^{* *}$ \\ Recibido: 13 de octubre de 2015 \\ Enviado a pares evaluadores: 27 de octubre de 2015 \\ Aprobado por pares evaluadores: 26 de enero de 2016 \\ Aprobado por comité editorial: 28 de enero de 2016
}

\section{RESUMEN}

$\mathrm{El}$ individuo es un elemento determinante para la historia de Occidente. Su surgimiento responde a fenómenos sociales de los siglos XVIII y XIX; la creación y crisis del Estado-nación como modelo de organización, si bien individualista y competitiva, ha mostrado ser insuficiente para atender y comprender a los individuos como particulares e irreductibles a la jurisprudencia colectiva. Esta crisis repercute en las críticas al Estado-nación realizadas por posturas acérrimamente individualistas como la de Max Stirner, autor de El único y su propiedad, quien planteó la irreductibilidad del hombre a cualquier manifestación social y teórica que se pretenda superior al individuo.

Palabras clave: liberalismo, propiedad, irreductible, socialismo, individuo, Estado.

Este texto hace parte de la investigación Feuerbach: La universalización del Hombre. ¿Subordinación o eliminación de la singularidad del hombre concreto en el proyecto humanista de Feuerbach?, inscrita en la Maestría en Filosofía de la Universidad de los Andes.

** Filósofa de la Universidad de Antioquia y candidata a magíster en Filosofía de la Universidad de los Andes. Correo electrónico: cristina1856s@gmail.com 


\section{The Implacable Individual. Deviation of Modern Liberalism and Socialism}

\section{ABSTRACT}

The individual is a decisive element for the Western history. Its emergence responds to social phenomena of the $18^{\text {th }}$ and $19^{\text {th }}$ centuries; the creation and crisis of the State-Nation as an organization model, despite its individualist and competitive nature, has proven to be insufficient to assist and compromise the individuals as particular and implacable parties of collective jurisprudence. This crisis has an impact on the criticism to the State-Nation made with extremely individual opinions such as that of Max Stirner, the author of "El Unico y su Propiedad," who spoke about the implacable nature of man before any social and theoretical manifestation alleged as superior to the individual.

Key words: Liberalism; property; implacable; socialism; individual; State. 


\section{Introducción}

La sustitución del Antiguo Régimen en Europa occidental que impulsó la caída de la monarquía encabezada por Luis XVI durante la Revolución Francesa tuvo como trasfondo una comprensión del individuo como ser libre y soberano, capaz de ser mucho más que un "engranaje" perteneciente a una colectividad que, sin dudarlo, lo subordinaba a la homogeneidad.

No está de más recordar que las sociedades monárquicas hacían esfuerzos extravagantes para cultivar la unión entre todo el colectivo social, tal como afirmó Arno Mayer:

[...] La familia real y los notables de la realeza dominaban el calendario de ceremonias del Estado, que estaba más vinculado a la cultura alta que a la baja. La sucesión de ritos cívicos espectaculares reforzaba las ideas, los valores y los sentimientos de hegemonía en que se apoyaban las élites preburguesas. Aquél ritual político también integraba a los estamentos inferiores al satisfacer su ansia de espectáculos esplendorosos, que era la contrapartida de la pasión por la jerarquía estricta entre los estamentos superiores (Mayer. 1981, p. 132).

La base sobre la cual se instauraba y dominaba toda la monarquía era la idea clara y práctica de entender que la colectividad era más importante que cualquier individuo. Incluso el monarca, único hombre que podía decidir por y para sí mismo, estaba atado a un andamiaje de responsabilidades y maneras de ser y hacer que eran aprendidas por tradición durante toda su formación como soberano de la nación. De aquí que propiamente el individuo, como soberano de sí, no existía en el antiguo régimen.

La Revolución de 1789 tuvo bastantes inconvenientes. De hecho, al abordar el acontecimiento desde una retrospectiva histórica, el Régimen del terror que se impuso al culminar la revolución sería solo el inicio de una época beligerante y vertiginosa en el escenario político de la Francia del siglo XIX. Sin embargo, lo que cabe señalar para el tema que aquí se trata es que no solo en Francia, sino en toda Europa, este siglo representó la llegada con fuerza y propiedad del individuo emergido desde el mismo clamor de libertad de la sociedad civil.

Surgen las teorías políticas más influyentes en los escenarios políticos modernos: el liberalismo y el socialismo intentando apropiarse del individuo en diferentes horizontes de lo político.

El liberalismo consideró, apoyado en las teorías contractualistas, que la voluntad del individuo debía ser salvaguardada por el Estado. A su vez, la libertad se convirtió en un derecho fundamental, limitada solo para garantizar el bienestar y la protección de todos los ciudadanos. 
Por otra parte, el socialismo encabezado por Marx y Engels acusó al individuo de estimarse tan libre como para poner en riesgo la igualdad social, cayendo en los excesos de la acumulación de la propiedad. De entrada, fijaron que el individuo solo podía entenderse como libre dentro de un comunismo, una vez superado cualquier tipo de asociación individuo/libertad/capital.

Pero en medio de estas teorías y sus creadores que cegaron con su atractivo esplendor al siglo XIX, se encontraba un joven perteneciente al Círculo de los libres en el Berlín de 1846 conocido en el mundo editorial como Max Stirner quien, señalando la incapacidad del liberalismo y del socialismo para comprender al individuo más allá de un contexto estrictamente político, realizó críticas a los mismos, basadas en la incapacidad para proponer un modelo de organización donde el individuo no fuera entendido solo como un ser libre, sino ante todo como único y singular. De hecho, en su obra más reconocida El único y su propiedad, Stirner rechaza el concepto de individuo por su frecuente asociación al liberalismo y propone que al entenderse como único, el hombre será capaz de proponer un escenario social que se adapte a sus necesidades y no uno en el cual él debe adaptarse como ocurre en el liberalismo y el socialismo. "Durante siglos el hombre ha basado su causa sobre terceros: Dios, el monarca, el Estado. Porque las sociedades nunca se han sabido edificar sobre sí mismas" (Stirner. 2005, p. 234).

La crítica de Stirner al liberalismo y el socialismo por su comprensión sesgada y amañada de un individuo moderadamente libre e igual a otros será el objetivo del presente escrito. Asimismo, se abordará el planteamiento stirneriano que conlleva prescindir del concepto mismo de individuo para entenderlo como único, un egoísta (en una redefinición del concepto donde es entendido como el hombre que arremete contra todo lo "sagrado" que pueda limitarle o intente "determinarlo"), capaz de apropiarse de su vida y liberarse de todo lo que le oprime, incluso de la idea liberal de libertad. Cabe anotar que este texto es solo un esbozo introductorio al pensamiento de Max Stirner.

\section{Precedente histórico: el individuo más allá del Estado-nación}

La idea de hombre como individuo único e irreductible, que pudiera servirse de la sociedad y, a su vez, que la sociedad se sirviera de sus talentos y trabajos para el desarrollo de la misma fue el fundamento filosófico de la transfiguración de valores colectivos a valores individuales que intentaron las revoluciones liberales de finales del siglo XVIII con la creación del Estado-nación.

El tercer Estado, aunque intentó cambiar el ordenamiento monárquico basado en un sistema de privilegios (donde lo que delimitaba la existencia del hombre era su función dentro del colectivo) por uno incluyente que reconociera como 
igual a cada uno de sus miembros y libre en su hacer a cada individuo no tuvo gran éxito, como afirma Arno Mayer en La persistencia del antiguo régimen, al no permear en los imaginarios sociales de las personas sujetadas a modelos serviciales de esclavitud.

Asimismo, el intento de sustitución se advirtió persuadido por los nuevos líderes políticos pertenecientes a la antigua monarquía, al seguir perpetuando el sistema de privilegios opuesto al sistema de derechos iguales para cada ciudadano que concebía el ideario del nuevo ordenamiento político, basado en los preceptos de igualdad y libertad devenidos de la comprensión del hombre como individuo.

Para 1840 el señalamiento al Estado-nación como un fracaso tomó fuerza en los sectores desfavorecidos de la sociedad y en las mentes inconformes de algunos intelectuales como Prohudon, Marx o Engels que esperaban aún el cumplimiento de la promesa de igualdad y libertad (práctica y no formal) como derechos comunes y factibles, y no solamente como meros formalismos institucionales, señalando al nuevo gobierno como un fracaso que debió ser eliminado durante la Revolución. En palabras del autor de la frase "La propiedad es un robo", el gobierno no era más que una forma sedimentada de oponerse a los ideales revolucionarios:

¿Quién se opone en 1989 a la revolución? El gobierno.

El gobierno, a pesar de la iniciativa que había sido forzado a tomar, se opuso tanto a la revolución en 1789 que fue preciso, para constreñirle, llamar a la nación en que el pueblo arrastró al gobierno al estrado como una víctima al sacrificio, sacrificio que levantó un régimen totalitario. (...) Ciertamente, estoy lejos de pretender que el pueblo, que quería la revolución, no tuvo razón para hacerla; digo sólo que el gobierno, al hacer resistencia, obedecía a su naturaleza y es lo que nuestros padres no comprendieron. En lugar de castigar a un hombre, de condenar una forma, era al principio a quien había que atacar, era el gobierno fuese de la ideología que fuese, el que había que ofrecer en holocausto a la revolución (Proudhon. 1947, p. 43).

Pero Proudhon aún se mostraba expectante ante la idea de crear un Estado que amparara los ideales revolucionarios; aún creía en la revolución y su capacidad para brindarle al pueblo su reconocimiento como pueblo libre.

Johann Kaspar Schmidt conocido bajo el seudónimo de Max Stirner fue mucho más escéptico. Pensó que el gobierno no podía deslindarse de formas represivas. Publicó entonces a principios de octubre de 1844 El único y su propiedad. De tono anti-intelectualista, iconoclasta e irónico, la obra hizo una reflexión crítica y burlona del Estado-nación por enquistarse en el modelo monárquico que intentaba demoler y, en consecuencia, limitar nuevamente al hombre en favor de la colectividad y en detrimento de su comprensión como individuo. 
El único también señaló que las colectividades, sean políticas, morales o sociales, eran inaceptables para el hombre por someterle al cumplimiento de valores morales, derechos civiles, normas éticas y principios universales, a expensas de restricciones a la voluntad individual.

Stirner profundizó su argumentación vilipendiosa de los colectivos políticos, sociales y/o morales. Los expuso como obstáculos que el hombre que gozara del reconocimiento de sí como único y particular debía superar para el despliegue de toda su fuerza, poder e individualidad, facultades estas que, lejos de dependencias colectivas, le permitirían apropiarse al hombre de todo aquello de lo que fuese capaz. Destacó el filósofo de Berlín la apropiación como facultad natural del yo, distinta a la noción de propiedad como propiedad otorgada que identificaba el tercer Estado.

Como se explicará a continuación, para Stirner, el problema de un gobierno que repetía las formas colectivas de represión al individuo no era, quizá, el mayor inconveniente, sino que las subsiguientes propuestas, como el liberalismo o el socialismo que intentaron mitigar la pobreza y la miseria en la que seguía la mayoría de los individuos después de la sustitución del antiguo régimen, fueran ajenas a reconocer al individuo como un único, para utilizar en beneficio de la libertad colectiva o la igualdad de todos.

\section{La homogeneización del individuo en el marco del liberalismo}

La efervescencia de una época o de la civilización por la "cuestión social" desvela que el individuo sigue a la sombra de todo. Los estudios antropológicos de pensadores como Luis Dumont presentan que los hombres organizados no saben fundar sociedades sobre sí mismos, es decir, sobre sus necesidades individuales, sino sobre terceros (Dios, monarca, Estado), fuese por ingenuidad, como apunta Maitron en su libro Ravachol y los Anarquistas (2003), o por ignorancia y temor.

Los liberales, antiguos burgueses que se sublevaron contra los privilegios del Estado monárquico, relegaron el lugar que ocupaban los intereses particulares para exaltar los intereses generales. Y si bien fue el individuo fundamento antropológico y moral del liberalismo, su modelo político solo fue posible efectuarlo por medio de limitaciones directas a la acción individual que reivindicaron al Estado como institución impersonal producto de la voluntad del pueblo.

Al respecto dirá Stirner: "La burguesía ha cumplido el sueño de tantos siglos; ha descubierto un señor absoluto (El Estado-Nación) cerca del cual otros señores no pueden ya elevarse como otras tantas restricciones. Ha producido el señor que él solo otorga "títulos legítimos" y sin cuyo consentimiento nada es legítimo" (Stirner, 2003, p. 143). 
El Estado como figura impersonal, designada para garantizar el cumplimiento de los derechos y de la ley, no requería de sus miembros la adhesión a una religión específica, ni la obediencia a otra persona. Tanto ateos como cristianos eran considerados libres dentro del Estado; también, quien poseía o no algún tipo de propiedad podía ser pensado como igual al propietario ante su jurisdicción. A este no le interesa ninguna acepción de persona; en ello reside su factum moral; su capacidad para medir a todos según derechos y leyes prescriptivas encierra su carácter igualitario.

Tal igualdad formalista del Estado-nación, antes de ser una garantía o un derecho del individuo, era un derecho del mismo ente institucional que al concebir a todos como iguales excluía cualquier rasgo de distinción entre sus miembros. El tercer Estado no reparó o estimuló características propias de cada persona; su virtud fue la identidad como homogeneidad o uniformidad de los ciudadanos que, por una parte, apareció como la garantía que encarna el derecho a recibir un trato igual, y por otra, cerró las puertas a las distinciones entre las personas y al reconocimiento de necesidades particulares.

El derecho a recibir un trato digno e igual a otros puede ser un valor importante para reforzar las relaciones de igualdad entre las mismas personas sin recurrir a la barbarie de la exclusión por credo, sexo, género o posesión, pero cierto es que tal derecho desconoce las distinciones particulares constitutivas de cada persona y que son mutiladas por tal categoría de igualdad. Ante la pregunta por el ¿Qué soy? el liberal proclamaba "soy un ciudadano" un concepto que solo puede concebirse en relación con un ordenamiento común; así dirá Stirner:

Todos gozamos de la "igualdad de los derechos políticos". ¿Qué significa esto? Simplemente que el Estado no tolera ninguna acepción de persona, que yo no soy a sus ojos, como el primer llegado, más que un hombre (un ciudadano) y no tengo ningún otro título a su atención. Poco le importa que yo sea gentilhombre e hijo de noble; poco le importa. (...) Hoy el Estado tiene una multitud de derechos que conferir como por ejemplo, el derecho de mandar un batallón, una compañía, el derecho de enseñar en una universidad; le pertenece disponer de ellos porque son suyos, porque son derechos del Estado, derechos políticos. Poco le importa a quién le cae en suerte, con tal que el beneficiado cumpla los deberes que le impone su función (Stirner, 2003, p. 144).

Al rebajar a los nobles y subir a los campesinos a la categoría de ciudadanos bajo el principio de igualdad ${ }^{1}$ la nación derrumbó pequeñas monarquías

1 La Revolución Industrial, que recién iniciaba para cuando Stirner escribió su obra, implicaba una despersonalización del trabajo que, en condiciones laborales de explotación, consideraba al individuo como una prolongación de la máquina, y donde toda distinción que hiciera de él algo más que una herramienta era aniquilada. Así, la igualdad insistente y recurrente también permitía despersonalizar al individuo ya no solo económicamente sino política y culturalmente al reducirlo a una homogeneidad donde los rasgos identitarios prevalecían sobre las diferencias. Al respecto véase: E. P. Thompson La formación de la clase obrera en Inglaterra (1989). 
y comunidades holistas, logrando imponer un sistema acrático perfecto y absoluto que no tenía que disputar con otro rey o feudo su soberanía. Ella - la nación- encierra en sí misma, so pretexto de la razón, la ley y lo justo, toda asociación y toda casta. Ante la soberanía de la nación, los individuos no guardan obediencia a un monarca. "El rey no era más que rey de castas y no rey de los ciudadanos; los individuos en la Nación sólo obedecen a la ley" (Stirner, 2003, p. 145). Una ley que los iguala a todos y los expone a una libertad otorgada dentro del marco de los deberes institucionales, como bien lo manifiesta Loewenstein:

En muchos países europeos las libertades individuales, sin embargo, están garantizadas por la constitución más formal que materialmente. Su validez absoluta estará restringida por las cláusulas limitativas, de forma que solo podrán ser ejercidas dentro de los límites de las leyes generales. (...) Esta práctica surgió ya en tiempo de la Declaración francesa de los derechos del hombre, lo que se puede aclarar históricamente por el hecho de que, para esta, la ley era la racionalización de la voluntad general. (Loewenstein, 1982, p. 396).

Ser una teoría que defiende sociopolíticamente las libertades del individuo, pero que, a su vez, debe restringirlas en beneficio del bienestar o la seguridad general es una contradicción fundamental del liberalismo y que el mismo Locke sostiene como "natural" de una sociedad de hombres que en un estado de naturaleza gozan de una libertad mayor, pero que ven amenazada su vida, su "propiedad". De hecho, para un individualista por excelencia, como lo era Locke, que la libertad no fuera completa sino "otorgada" y, de paso, restringida por el Estado era más conveniente para el individuo propietario como lo explica en un parágrafo de su Ensayo sobre el gobierno civil: "[...] los hombres al entrar en sociedad abandonan en manos de ella la igualdad, la libertad y el poder ejecutivo que tuvieron en el estado de naturaleza, para que de los tales disponga el poder legislativo, según el bien que la sociedad exigiere [...]" (Locke, 2005, p. 76).

Es así como se revela, incluso en un pensador absolutamente individualista como Locke, la importancia del bienestar colectivo. Esta importancia radica en salvaguardar la propiedad individual, pero a un precio que Stirner considera impensable, y es que la libertad no sea propia, sino otorgada por la ley.

Desde la postura stirneriana si se enfocase más en el individuo y menos en la divinización de la propiedad, la doctrina del liberalismo no podría por menos de prescindir del concepto de libertad otorgada por la ley, e incentivaría en los individuos la importancia de liberarse de todo aquello que constriñe su propia vida. 


\section{El individuo más allá de un régimen socialista}

Stirner no solo arremetió contra el liberalismo. También señaló a los proletarios principales simpatizantes del socialismo de Marx, no por querer educarse, como sí por perpetuar los valores del Estado-nación.

Los socialistas, al exigir libertad e igualdad, ya no ante la ley sino material, exigían, como consecuencia, la abolición de la propiedad privada en aras de una propiedad colectiva, una propiedad "de todos y para todos" o, en otras palabras, una propiedad colectivizada que les permitiría a todos poseer lo mismo en la medida del rendimiento de su trabajo.

En oposición al liberalismo originario que previó como argumento fundacional de su teoría que hubiese un solo soberano que gobernase y legitimase la libertad y la propiedad (el Estado), para los socialistas la directriz de su teoría sería que la sociedad fuese la insuperable poseedora. Su conclusión es que los individuos no posean, apuntando que la mejor manera de acabar con la propiedad individual es que la sociedad, sin cuerpo o materia identificable, sea la dueña y poseedora absoluta, pues "si nadie posee, todos poseerán" nada, pero para los socialistas que todos posean nada y que la sociedad lo posea todo era la garantía necesaria y suficiente para la igualdad ya no solo formal, sino práctica. Es así como la colectividad vuelve a aplastar al individuo en esa puja constante que ha sido la relación colectividad/individuo.

La petición socialista de igualdad material fue una consecuencia inevitable del liberalismo político que hizo a las personas iguales ante la ley, pero no otorgó una igualdad ante lo que poseen. Y si bien el rico y el pobre compartían una relación igualitaria como proveedores de bienes y servicios, dicha igualdad se extinguía en la condición de propietarios.

En este sentido al hablar de libertad los socialistas no solo propusieron una libertad frente a las personas o lo arbitrario como no coacción (libertad negativa), sino también frente a la posesión del otro, frente a la propiedad personal que monopoliza los medios de producción, a la vez que causaba miseria y hambruna en los desposeídos, y que, en tanto, dejaba inconclusa la idea de una igualdad entre las personas.

Los socialistas (Marx, Engels) se pensaron a sí mismos como los emisarios de la igualdad, no a medias o formal, sino completa. Su propuesta de igualdad era una organización que apremiara el bienestar de todos y la propiedad colectiva; una organización donde la igualdad no fuese un mero formalismo, como miembros ciudadanos del Estado, sino donde los hombres lograran identificarse como iguales (sin mediación del Estado) en cuanto su labor y sus posesiones. 
De aquí la dificultad que Stirner señaló: en tanto miembro del Estado-nación y como trabajador, al hombre se le desconoce su facultad de poseer ${ }^{2}$. En ambos regímenes se le niega al hombre la posibilidad de conocerse y desarrollar sus facultades innatas. "Tal es el segundo robo hecho a la "personalidad" en provecho de la "humanidad". No se deja al individuo ni el derecho de mandar ni el derecho de poseer: el Estado toma el uno, la sociedad toma lo otro" (Stirner, 2003, p. 159).

No es otra la igualdad material, o en un sentido más amplio que el formal del liberalismo originario, que la igualdad de ser todos trabajadores.

La doctrina liberal no logró salvaguardar al individuo como su fundamento filosófico y moral; por el contrario, ante la incapacidad de sobreponerse a un régimen monárquico, seguía por perpetuar un sistema de privilegios en el que el valor del hombre no se determinaba por sus capacidades individuales, sino por su poder adquisitivo.

Por su parte, el socialismo se mostraba menos interesado por el individuo, a quien acusaba de ser un concepto "burgués" al devenir del liberalismo, y se encargó, tras sus críticas al Estado laico (por persistir en una igualdad formal), mutilar cualquier rasgo distintivo del hombre, a expensas de la exaltación de "lo común" y colectivo que serviría a un modelo de organización materialmente igualitaria. Así en ambas teorías se intentó eliminar la comprensión del hombre como único e indeterminable y, con ello, despojarlo de sus facultades de apropiación, poder y fuerza.

$\mathrm{El}$ socialismo reduce las distinciones entre individuos al exponerlos a todos como trabajadores, ya que el esencialismo de la igualdad socialista es el trabajo, único valor que se aprecia entre los hombres y, por tanto, única cualidad por la que pueden ser evaluados como un miembro "bueno" de la sociedad, pues quien más produce es el mejor trabajador, el mejor elemento de la colectividad. Cabría contestar a la pregunta implícita y de manera sintética de ¿qué es un trabajador?, al mencionar que un trabajador es un productor para la comunidad, y su valor es el rendimiento para ella, quedándole imposibilitadas las actividades placenteras o enriquecedoras para sí mismo:

Todo placer de un espíritu cultivado está vedado a los obreros al servicio de otro; no les quedan más que los placeres groseros; toda cultura les está cerrada. Para ser buen cristiano basta creer; y creer es posible en cualquier situación que uno se encuentre; así la gente de convicciones cristianas no pone sus miras más que en la piedad de los trabajadores avasallados, su paciencia, su resignación, etc. Las clases oprimidas

Distinto a la posesión material que ofrece el liberalismo originario, la posesión es una facultad del hombre que se desarrolla en cuanto es el quién se apropia de lo que necesita para vivir, incluso de su libertad, que en ninguna circunstancia será otorgada por un tercero. 
pudieron en rigor "soportar" toda su miseria tan largo tiempo como fueron cristianas, porque el cristianismo es un maravilloso apagador de todos los murmullos y de todas las rebeliones. Pero no se trata ya hoy de ahogar los deseos, sino de satisfacerlos. La burguesía, que ha proclamado el evangelio de la alegría de vivir del goce material, se extraña de ver que esta doctrina encuentra partidarios entre nosotros, los pobres; ella ha mostrado que lo que la hace feliz no es ni la fe ni la pobreza, sino la instrucción y la riqueza; iciertamente así lo entendemos nosotros los proletarios!

La burguesía se ha liberado del despotismo y de la arbitrariedad individuales; pero ha dejado subsistir la arbitrariedad que resulta del concurso de las circunstancias y que se puede llamar la fatalidad de los acontecimientos; hay siempre una suerte que favorece y "gente que tiene suerte" (161) ${ }^{3}$.

Si un trabajo no deja tiempo para cultivarse a sí mismo o no permite o impulsa el desarrollo de sí, ese trabajo solo verá a los hombres como engranajes de la cadena de producción. De aquí que al trabajador, su labor no podrá satisfacerle sino abrumarle en la medida en que no retribuye satisfacción para él. En consecuencia, hablamos de esclavitud, ya que un trabajo que no produce primero satisfacción en el hombre es sometimiento y opresión.

Por ejemplo, imaginemos a un trabajador que le gustaría explorar sus gustos y placeres en el arte. Aquel hombre también trabaja barriendo las calles porque tiene necesidades que debe cubrir para existir, como vivienda y alimentación. Está visto que durante su jornada laboral, él no podrá acercarse al fin que se propuso, pues como bien lo dice Oscar Wilde "barrer durante ocho horas diarias la plazoleta enfangada cuando el viento sopla del Este es una situación penosa" (Wilde, 1977, p. 1298). Ningún provecho podrá ocasionar al hombre que obligado por las circunstancias materiales ejerce tal actividad.

Si el liberalismo se ahorra el derecho de "otorgar" la libertad a los individuos, el socialismo señala la libertad como "un privilegio burgués" que el trabajador no debe permitirse. Se puede concluir que tanto el liberalismo como el socialismo implican reformas parcializadas al antiguo régimen que siguen por priorizar la colectividad por encima de la individualidad, quedando nuevamente el individuo marginado en su unicidad y singularidad.

\section{Propiedad individual no, propiedad colectiva tampoco. Propiedad del individuo}

Los discursos políticos de la Modernidad que aparecieron con las revoluciones liberales no solo tomaron en cuenta el lugar que ocupaba el hombre en la socie-

3 Cabe recordar que Stirner no solo teorizó sobre los proletarios, él mismo padeció los desconsuelos propios de vivir en una necesidad constante, hostigado por la mala fortuna y condicionado por las exigencias de una labor que pide mucho de la persona y está —como todo trabajo— muy mal remunerada, la del docente. Pero tiempo después el autor cambia de clase, se vuelve un lumpen que de cara al abandono y los malos tratos, conoce de cerca la suerte de los miserables, de los desposeídos que poseen solo hambres. 
dad, sino también a quién pertenecían las cosas, si a la comunidad o al individuo. Cada doctrina, como el liberalismo y el socialismo, brindó una respuesta distinta (la propiedad individual del liberalismo en concordancia con la idea de posesión del antiguo régimen zanjaba para ellos el problema, y la propiedad colectiva del socialismo que conecta con la propuesta de una sociedad de trabajadores era la solución para los socialistas). Sin estar de acuerdo con ninguna de las dos concepciones, Stirner expuso su propia idea correlacionada con la facultad de apropiación individual.

La propiedad que no depende del reconocimiento del Estado, que no es sagrada ni colectiva, es la propiedad del hombre como Único. El profesor de Berlín denominaba propiedad a aquello que "yo" me apropio en cuanto uso de "mi" fuerza y poder para hacerlo. El hombre único "es la ausencia de determinaciones externas". Gestor de su propia determinación se apropia de las cosas, incluso de aquello que aparecería ante la jurisdicción de lo legislativo como colectivo, como apuntó el autor.

Se designa bajo el nombre de propiedad el poder limitado que yo tengo sobre las cosas (objeto, animal u hombre) de que puedo "usar a mi agrado". [...] pero la propiedad tiene por condición el poder. Lo que está en mi poder es mío. En tanto que mantengo mi situación de poseedor de un objeto, sigo siendo su propietario; no si se me escapa. [...] Propiedad y apropiación vienen, pues, a ser lo mismo. No es un derecho exterior a mi poder el que me hace legítimo propietario, sino mi poder mismo y sólo él; si lo pierdo, el objeto se me escapa. [...] Toda cosa es la propiedad de quien sabe tomarla y guardarlo, y queda siendo de él, en tanto que no le es recogida; así, la libertad pertenece al que la toma (Stirner, 2003, pp. 289-290).

Propiedad del único es propiedad incondicional sin más límites que los que el hombre está dispuesto a reconocer. Es lo que tiene bajo su poder, de lo que es capaz de apropiarse, disponer a su agrado e intercambiar a su antojo, como sus pensamientos sin sanción moral, política o cultural. Sus facultades de fuerza y voluntad son sus herramientas para hacerse poseedor de lo que tiene necesidad y precisa tener. Pero él en este sentido, valga aclarar, no es un poseído como podría estimársele al ciudadano que tiene por deber tributar por la declaración de su propiedad. El hombre único domina sus posesiones. Él es su creador, ellas sus criaturas. Esta idea de propiedad "indeterminada" es la piedra de toque que, como propuesta diferente al liberalismo y el socialismo, puntualiza la crítica stirneriana a estas doctrinas por la reducción que hacen del hombre único a favor de organizaciones políticas y sociales.

La pregunta acusadora que podría hacerse en estas instancias al autor alemán es sencilla: "¿Por qué no abolir la propiedad en lugar de llevarla por una tercera vía en concordancia con la capacidad de apropiación del hombre?". 
La argumentación stirneriana es clara al respecto. Los socialistas intentan abolir cierto tipo de propiedad, la individual, sin pasar por alto los monopolios, el dinero etc., pero no erradican la propiedad colectiva, es decir, la "sociedad poseedora" que combate solamente el atomismo y no la servidumbre del trabajador. Que la propiedad sea de "todos" solo significa que no es de alguno, y con ello no es claro el asunto de la superación de la servidumbre a la propiedad.

Decir que "la propiedad es un robo" tampoco resuelve la distribución de las cosas, sino que agudiza el problema y tiene como consecuencia el robo, porque independiente de llamar a la propiedad colectiva o privada, un individuo que se quiera apropiar de algo, aún de las herramientas para su trabajo, será considerado como un ladrón en ambos casos de propiedad. Entonces la propiedad no se resuelve con la expresión "para todos, todo"; tal proposición no desaparece la propiedad, solamente intenta hacerla colectiva en cuanto es la sociedad quien posee.

Recordemos que en España las comunas anarquistas que florecieron a principios y mediados del siglo XX tuvieron como punto neurálgico de sus discusiones el asunto de la propiedad, porque al no tener resuelto qué tipo de propiedad era mejor para la comuna, si individual o colectiva, estas ingresaron en serias pugnas que empezarían a destruir el ideal de solidaridad anarquista ${ }^{4}$.

En este sentido, la disputa no tendría que ser sobre si la propiedad deba entenderse en términos colectivos o individualistas, sino sobre a qué nos referimos por propiedad.

Para Stirner la propiedad no es cosa distinta a lo que nombramos como fuerza, poder y capacidad para tomar las cosas necesarias para "mí". De aquí que no la intente abolir, sino que renuncie a señalarla como disociadora o problemática para las asociaciones de hombres. Al no ser "sagrada" la propiedad, al cada uno poseer poder y fuerza, esta se convierte en algo usual como nuestras facultades de conocer, entender y aprender propias de la especie:

4 Cabe precisar aquí que, los anarcocolectivistas, en la línea de Proudhon o Bakunin, argumentaban a favor de la propiedad individual y el beneficio producto del propio trabajo "A cada uno, según su esfuerzo". A partir de 1885, y bajo la influencia de Kropotkin, empieza a desarrollarse el anarcocomunismo apelando a la colectivización de la propiedad "a cada uno según sus posibilidades". Ambos movimientos durante algunas décadas se encuentran en vías paralelas que repercuten en confrontaciones muy fuertes. Historiadores como Josep Termes consideran la fuerza sindical de los grupos anarquistas (alrededor de la CNT como herederos de las tesis colectivistas). Por otro lado, los grupos insurreccionalistas, especialmente campesinos y obreros, fueron los más partidarios del anarcocomunismo. Entre los historiadores del anarquismo español no hay un acuerdo unánime sobre una cuestión todavía polémica. Cabe resaltar que Stirner fue, particularmente, más acogido entre los "anarcocomunistas insurreccionales", en tanto que los colectivistas, especialmente en la primera década del siglo XX, eran más dados al compromiso con instituciones como los partidos. Véase El anarquismo individualista en España (1923-1938). 
La propiedad no puede, ni debe pues, ser abolida; lo que hay que hacer es arrancársela a los espíritus para hacer de ella mi propiedad. Entonces se desvanecerá esa ilusión de que yo no soy autoridad para tomar todo aquello de que tengo necesidad.

"iPero de cuántas cosas tiene el hombre necesidad!" El que tiene necesidad de mucho y se ingenia para tomarlo, ¿se ha creído nunca falta por apropiárselo? Napoleón ha tomado la Europa y los franceses Argel. Lo que convendría es que la plebe a la que el respeto paraliza aprenda, en fin, a procurarse lo que le hace falta. Si ella va demasiado lejos y si os juzgáis ofendidos, ipues bien! Defendeos; no debéis hacerle regalos benévolamente. Cuando ella aprenda a conocerse, o más bien, cuando los de la plebe aprendan a conocerse, dejarán de formar parte de ella por lo mismo rehusarán vuestras limosnas.

[...] La cuestión de la propiedad no es, creo haberlo mostrado, tan sencilla de resolver como se lo imaginan los socialistas y hasta los comunistas. No será resuelta más que por la guerra de todos contra todos. Los pobres no llegarán a ser libres y propietarios más que cuando se insurreccionen, se subleven, se eleven. Les deis lo que les deis querrán siempre más, porque no quieren nada menos que la supresión de todo don (Stirner, 2003, pp. 297-298).

\section{¿Quién es el individuo stirneriano? El único}

El "Yo destructor" como "Yo creador", la nada que anula la apuesta por las colectividades políticas o sociales, Es el único que durante muchos años ha sido sepultado y vilipendiado, por los prejuicios que aterrizan ante un Stirner y una obra antirracionalista, anti-filosófica, anti-metafísica, inhumana, inmoral e iconoclasta. Stirner criticó en pleno nacimiento del liberalismo y el socialismo, que en cuanto potencia creadora, el hombre no debía esperar que la colectividad lo reivindicara como único e irreductible. Por el contrario, tendría que sobreponerse, burlarse si fuese preciso, de toda institución, de todo lo colectivo; dimensionar sus capacidades de poder, fuerza y apropiación para crear relaciones no de dependencia, sino de goce y armonía con la vida y con su entorno. "Todo gira en torno a ti; tú eres el centro del mundo exterior y el centro del mundo de los pensamientos. Tu mundo llega tan lejos como tu capacidad de aprehenderlo, y lo que aprehendes, eso es tuyo, por el mero hecho de aprehenderlo. Tú, que eres Único, eres único solo junto a tu propiedad" (Stirner, 2013, p. 108).

Este único no necesita que le otorguen su libertad; este individuo aprende a vivir para sí mismo en asociación con sus pares. El único sabe que necesita de otros únicos para vivir. No es un individuo atomizado, por el contrario, ejerce sus facultades y las desarrolla en un contacto mutuo con los otros y sus actitudes también únicas e irreductibles. Egoístas por naturaleza, Stirner no censura el egoísmo, por el contrario lo prevé como la motivación fundamental de la solidaridad. Cuando el individuo es solidario es porque es capaz de entender la situación del otro desde su propia perspectiva. En palabras del autor Bávaro: 
Pero cuando te hayas olvidado de ti, ¿has desaparecido del todo? Cuando no piensas en ti mismo, ¿has dejado de ser algo? Cuando miras a los ojos de tu amigo o meditas sobre una alegría que le quisieras deparar; cuando levantas la mirada hacia las estrellas, cavilas sobre sus leyes, o acaso les encargas saludos para que los lleven a una alcoba solitaria; cuando miras por el microscopio y te pierdes en el bullicio de los infusorios; cuando acudes en socorro de un hombre amenazado por el fuego o por el agua, sin reparar en el peligro que tú mismo estás corriendo: entonces ciertamente no estás pensando en ti mismo; te olvidas de ti. Pero ¿es que sólo eres cuando estás pensando en ti mismo? ¿Acaso vienes a menos cuando te olvidas de ti? ¿Acaso eres solamente por gracia de la conciencia de sí? ¿Quién no se olvida de sí a cada instante, quién no se pierde de vista a sí mismo mil veces cada hora?

Pues bien, este olvido de sí, esta manera de perderse a sí mismo no es más que disfrute de nuestro mundo, de nuestra propiedad, esto es, disfrute del mundo. (Citado por Stirner, 2013, pp. 108-109).

Este "perderse a sí mismo" de manera que se es en el mundo y se disfruta en él sería para Stirner el objetivo principal de una teoría que osaría de proclamarse a sí misma individualista o. por lo menos, que considere las necesidades de cada persona.

\section{A manera de reflexión}

La figura de un individuo único y singular es quizá difícil de comprender. Quizá si se imagina a un defensor acérrimo del individuo, que denuncie cualquier atropello contra el mismo, podría entenderse a Stirner en su escepticismo y críticas contra los modelos políticos más sobresalientes de la Modernidad. De hecho, el reconocimiento de un único no es una eventualidad social o estatal. Para una postura radical e irreverente como la del profesor de Berlín, cada persona es quien decide por autodeterminación reconocerse a sí mismo como único.

La actividad social no debe estimarse más que como una "asociación" y no como un sedimento de una colectividad opresora. Sin embargo, para que el único entienda que la mayoría de los obstáculos que enfrenta proviene de una vida homogeneizada por una comunidad que limita su libertad o fomenta la igualdad, tendría que empezar por hacer de sí mismo su propia causa y su propio fin. En otras palabras, no rendir culto a valores externos e impuestos; no entregarse por completo a actividades inoficiosas para su propio espíritu en provecho de otros. La causa primera de todo individuo tendría que ser el "conocerse a sí mismo":

Una vez el hombre cifre su honor en sentirse a sí mismo, conocerse a sí mismo y actuar por sí mismo, esto es, en el sentimiento de sí, la conciencia de sí y la libertad, se esforzará por si solo por desterrar la ignorancia, que le hace del objeto ajeno e incomprendido una barrera y un impedimento a su conocimiento de sí (Stirner, 2013, p. 47). 
Si la voz de Stirner hubiese sido lo suficientemente fuerte en 1846, quizá se hubiesen hecho cambios teóricos y políticos a tiempo para evitar caer en la ilusión de los Estados modernos de creer que vivimos como individuos libres. La sociedad liberal que "otorga derechos", o socialista, que aprecia la igualdad en detrimento de la singularidad individual, no son nuevas sino viejas reformas al antiguo régimen. Quizá si en los anales del Estado-nación se hubiese estimado que no se trata solo de teorías políticas, sino, más importante aún, de maneras de comprender a los hombres, las propuestas tendrían en cuenta la importancia del aporte a una sociedad que puede hacer individuos singulares y únicos, hombres que para Stirner son indeterminados.

\section{Referencias bibliográficas}

\section{Primaria}

Locke, J. (2005). Ensayo sobre el gobierno civil. Madrid: Alianza.

Loewenstein, K. (1982). Teoría de la constitución. España: Ariel.

Mayer, A. (1984). La persistencia del antiguo régimen. Madrid: Alianza.

Renaut, A. (1993). La era del individuo. Barcelona: Destino.

Stirner, M. (2003). El único y su propiedad. España: Sexto Piso.

Stirner, M. (2013). Escritos menores. España: Pepitas de Calabaza.

Thompson, E. (1989). La formación de la clase obrera en Inglaterra. Madrid: Alianza.

Wilde, O. (1977) El alma del hombre bajo el socialismo. En Obras completas. Madrid: Aguilar.

\section{Secundaria}

Díez, J. (2000). El anarquismo individualista en España (1923-1938). Barcelona: Virus.

Guerin, D. (1977). Ni dios ni amo (I). Madrid: Campo Abierto.

Marx, K. Engels, F. (2005). La sagrada Familia. Buenos Aires. Claridad. 